\title{
A Rare Case of Cardiorespiratory Arrest after Metoclopramide Infusion
}

\author{
Cássio Alexandre Oliveira Rodrigues, ${ }^{(1)}$ Eduardo Queiroz da Cunha, ${ }^{(1)}$ Priscila Ribeiro de Paula, ${ }^{(1)}$ Rand Randall \\ Martins ${ }^{(1)}$ \\ Hospital Universitário Onofre Lopes (HUOL), Universidade Federal do Rio Grande do Norte (UFRN), RN - Brazil
}

\section{Introduction}

Commonly used as an antiemetic and prokinetic agent, especially in critically-ill patients to reverse gastroparesis and increase in gastric emptying, metoclopramide use can result in important adverse reactions, leading the European Medicines Agency to recommend its use at minimum doses and for a short period of time, due to the risk of neurotoxicity. ${ }^{1}$

Although often associated to neurological events, reactions to this drug affecting the cardiovascular system are less frequent when compared to those that affect the central nervous system. There have been reports of total atrioventricular block ${ }^{2}$ and sinus arrest, ${ }^{3}$ but the occurrence of metoclopramide-induced cardiorespiratory arrest (CRA) is a rare and poorly described event.

Considering the scarcity of reports and its widespread use in health services, we described a case of CRA in a 21-yearold young woman immediately after the administration of metoclopramide for the treatment of diabetic gastroparesis. This report was approved by the Research Ethics Committee of HUOL (CAAE: 73091717.0.0000.5292). The free and informed consent form was signed by the patient.

\section{Case Report}

This is the case of a 21-year-old female patient with type I diabetes, using analogous insulin (lispro and glargine), allergic to dipyrone and with previous use of gabapentin and amitriptyline for the treatment of chronic

\section{Keywords}

Metaclopramide/Adverse effects; Drug Prescriptions/ standards; Heart Arrest; Pharmacokinetics; Drug Related Side Effects and Adverse Reactions. pain. During anamnesis, previous cardiovascular disease was not reported or evidenced.

The patient was treated in an emergency unit due to diabetic ketoacidosis, triggered by poor diet and medication adherence when she developed lowering of consciousness level and bronchoaspiration episode, requiring orotracheal intubation and mechanical ventilation. After 24 hours, the patient was transferred to the intensive care unit (ICU) of our institution, showing increased nitrogenous waste, refractory to clinical measures and thus, renal replacement therapy with hemodialysis was indicated due to refractory acidosis and hypervolemia. There was no report of previous chronic kidney disease.

For the treatment of aspiration pneumonia, cefepime and clindamycin were used during the first three days of hospitalization, later modified for meropenem and amikacin due to the suspicion of a new infectious condition. The patient was under continuous sedation with fentanyl and midazolam, with a Richmond agitation sedation scale (RASS) target score $=0$ and required hemodynamic support with norepinephrine $(0.1 \mathrm{mcg} / \mathrm{kg} / \mathrm{min})$ for a short period of time at the beginning of hospitalization, withdrawn on the $4^{\text {th }}$ day at the ICU. During this period, treatment with metoclopramide at a dose of $10 \mathrm{mg}$ (iv, $8 / 8$ hours) diluted in $100 \mathrm{~mL}$ of $0.9 \%$ sodium chloride $(0.1 \mathrm{mg} /$ $\mathrm{mL}$ ) was started for treatment of diabetic gastroparesis. Three days later, as she required greater fluid restriction, the prescription was adjusted: the saline solution was replaced by $18 \mathrm{~mL}$ of bidistilled water $(0.5 \mathrm{mg} / \mathrm{mL})$. The route of administration and dose were maintained.

After initial clinical measures, there was a satisfactory evolution of the clinical condition with better glycemic control, regression of gastroparesis and discontinuation of hemodialysis due to sustained improvement of 
renal function. She remained under sedation and mechanical ventilation until the beginning of the ninth day, being weaned without any major incidents. The prokinetic agent prescription was maintained even after gastroparesis improvement. However, by the tenth day, the administration of bolus metoclopramide was immediately followed by bradyarrhythmia and CRA (Cardiorespiratory Arrest) with Pulseless Electrical Activity (PEA). The management was performed according to the ACLS (Advanced Cardiovascular Life Support) protocol, with CPR (Cardiopulmonary Resuscitation), orotracheal intubation and administration of epinephrine ( $1 \mathrm{mg}$ intravenously). The condition was reversed after one cycle, with no evidence of sequelae and followed by extubation one hour after the CRA.

The electrocardiogram performed later showed sinus rhythm, with an electrical axis around $+60^{\circ}$, with no changes in the $\mathrm{P}$ wave or PR interval, heart rate of $83 \mathrm{bpm}$, QRS interval with normal morphology and amplitudes, no changes in the ST-segment and T wave and QTc interval of $376 \mathrm{msec}$.

The previously performed transthoracic echocardiogram, carried out on the $4^{\text {th }}$ day of ICU stay, had shown only discrete mitral regurgitation, without segmental alterations, with normal-sized cardiac chambers, with an ejection fraction of $69 \%$ (Teichholz). Before the event, the patient was breathing ambient air, with stable vital signs (HR: 98 bpm; blood pressure levels: 121x71 mmHg; RR: 20 breaths per minute; $\mathrm{SO}_{2}$ : 99\%; temperature: $36.3^{\circ} \mathrm{C}$ ), conscious and oriented, with no alterations at the physical examination. The laboratory exams showed normal glycemia (112 mg/dL; and $127 \mathrm{mg} / \mathrm{dL}$ after the event) and potassium $(4.6 \mathrm{mEq} / \mathrm{L})$ levels and arterial blood gas analysis with mild respiratory alkalosis ( $\mathrm{pH}: 7.469 ; \mathrm{PO}_{2}: 114.4 \mathrm{mmHg} ; \mathrm{PCO}_{2}$ : $\left.31.8 \mathrm{mmHg} ; \mathrm{HCO}_{3}: 23.3 \mathrm{mmol} / \mathrm{L} ; \mathrm{BE}: 0.5 \mathrm{mmol} / \mathrm{L}\right)$.

Immediately after the adverse reaction, the prescription of metoclopramide was modified to "if necessary" and withdrawn from the prescription for the next day. The patient was discharged from the ICU on the following day without further complications. Eight days later, after diabetes treatment adjustments, she was discharged from the hospital and is currently being followed in an outpatient endocrinology unit.

\section{Discussion}

Blockade of the dopaminergic pathways (D1 and D2 receptors) associated with gastrointestinal motility inhibition is characterized as the pharmacodynamic basis of metoclopramide, and in particular, blockade of central D2 receptors by the drug can cause dystonic extrapyramidal reactions and increase prolactin levels, considered the most common mechanisms of metoclopramide toxicity. ${ }^{4}$ Moreover, this drug is a derivative of procainamide $\mathrm{e}^{3}$ and its cardiotoxic effect seems to involve the blocking of sodium channels, affecting the cardiac electrophysiology. ${ }^{5}$

Despite the arrhythmogenic potential, there have been few reports of CRA associated with its use. These involved patients of both genders between 28 and 66 years of age, with a variety of clinical conditions and CRA after infusion of the medication (Table 1). There have been reports of five episodes following metoclopramide infusions in one patient with subarachnoid hemorrhage, two episodes of asystole in one patient at the postoperative period of partial mastectomy, one case in a patient admitted for abdominal pain and emesis, one report of bradycardia followed by cardiac arrest in a patient at the preoperative period for gastrectomy and one case of a patient with scleroderma who had CRA five minutes after the medication infusion. ${ }^{4,6-9}$

All these cases have in common the intravenous administration of the same bolus dose of metoclopramide. It seems that the infusion time can have an impact on the occurrence of the event, such as extrapyramidal reactions. ${ }^{10}$ It is noteworthy that there were no complications when the medication was administered by slow infusion in saline solution during the first days of treatment.

Other medications prescribed on the day of the event were also evaluated. In addition to metoclopramide, unfractionated heparin, glargine and regular insulin, meropenem, methylcellulose eye drops, pantoprazole, nystatin, and topical triamcinolone were prescribed. At the time of the event, the patient remained under hydration with lactated Ringer's solution in a continuous intravenous infusion at $21 \mathrm{~mL} /$ hour. Meropenem and methylcellulose were scheduled at the same time as metoclopramide but had not yet been administered. We emphasize the patient's clinical stability on this day, including a scheduled ICU discharge.

According to the Naranjo algorithm, CRA as a consequence of metoclopramide administration may be characterized as a probable adverse reaction (7 points). The risk can be higher in critically-ill patients with predisposing conditions, use of multiple medications, or it may be associated with prolonged use without 
Table 1 - Characterization of case reports involving CPA after metoclopramide use

\begin{tabular}{|c|c|c|c|}
\hline Reference & Patient & Comorbid conditions & Metoclopramide \\
\hline Bentsen, Stubhaug $(2002)^{5}$ & 41 years, male & $\begin{array}{c}\text { SAB; } \\
\text { ICH; Pneumonia; }\end{array}$ & $10 \mathrm{mg}$, iv \\
\hline Tung, Sweitzer, Cutter (2002) ${ }^{4}$ & 38 years, female & $\begin{array}{c}\text { Scleroderma; SAH; } \\
\text { Gangrene; }\end{array}$ & $10 \mathrm{mg}$, iv \\
\hline Grenier, Drolet $(2003)^{6}$ & 66 years, female & $\begin{array}{l}\text { PO partial mastectomy; } \\
\text { DM2; }\end{array}$ & $10 \mathrm{mg}$, iv \\
\hline Rumore et al. $(2011)^{8}$ & 62 years, female & $\begin{array}{c}\text { Preoperative gastrectomy; } \\
\text { Obesity; }\end{array}$ & $10 \mathrm{mg}$, iv \\
\hline Al-shaer, Mustafa, Scalese $(2015)^{7}$ & 28 years, male & $\begin{array}{c}\text { Abdominal pain; emesis; } \\
\text { SAH; DLP; }\end{array}$ & $10 \mathrm{mg}$, iv \\
\hline
\end{tabular}

justified need. In our case, the use of metoclopramide persisted even after the gastroparesis was reversed, which may have contributed to the event. However, we emphasize the possibility of the rapid bolus infusion risk, due to its well-known neurotoxicity and, apparently, the cardiotoxic potential evidenced by the sodium channel blockade.

\section{Author contributions}

Conception and design of the research: Rodrigues CAO. Acquisition of data: Rodrigues CAO, Martins RR. Analysis and interpretation of the data: Rodrigues CAO, Cunha EQ, Paula PR, Martins RR. Writing of the manuscript: Rodrigues CAO, Cunha EQ, Martins RR. Critical revision of the manuscript for intellectual content: Rodrigues CAO, Cunha EQ, Paula PR, Martins RR. Monitoring of patient and identification of reaction: Paula PR.

\section{References}

1. van der Meer YG, Venhuizen WA, Heyland DK, Van Zanten ARH. Should we stop prescribing metoclopramide as a prokinetic drug in critically ill patients? Crit Care. 2014;18(5):502.

2. Midttun M, Oberg B. Total heart block after intravenous metoclopramide. Lancet. 1994;343(8890):182-3.

3. Malkoff MD, Ponzillo JJ, Myles GL, Gomez CR, Cruz-Flores S. Sinus arrest after administration of intravenous metoclopramide. Ann Pharmacother. 1995;29(4):381-3.

\section{Potential Conflict of Interest}

No potential conflict of interest relevant to this article was reported.

\section{Sources of Funding}

There were no external funding sources for this study.

\section{Study Association}

This study is not associated with any thesis or dissertation work.

\section{Ethics approval and consent to participate}

This study was approved by the Ethics Committee of the Hospital Universitário Onofre Lopes under the protocol number 37091717.0.0000.5292. All the procedures in this study were in accordance with the 1975 Helsinki Declaration, updated in 2013. Informed consent was obtained from all participants included in the study.
4. Bentsen G, Stubhaug A. Cardiac arrest after intravenous metoclopramide - a case of five repeated injections of metoclopramide causing five episodes of cardiac arrest. Acta Anaesthesiol Scand. 2002;46(7):908-910.

5. Stoetzer C, Voelker M, Doll T, Heineke J, Wegner F, Leffler A. Cardiotoxic antiemetics metoclopramide and domperidone block cardiac voltagegated Na+ channels. Anesth Analg. 2017;124(1):52-60.

6. Tung A, Sweitzer B, Cutter T. Cardiac arrest after labetalol and metoclopramide administration in a patient with scleroderma. Anesth Analg. 2002;95(6):1667-8 
7. Grenier $Y$, Drolet P. Asystolic cardiac arrest: an unusual reaction following IV metoclopramide. Can J Anaesth. 2003;50(4):333-5.

8. Al-shaer MH, Mustafa MS, scalese MJ. Metoclopramide-induced asystolic cardiac arrest. Ann Pharmacother. 2015;49(5):610-1.

9. Rumore MM, Lee S, Wang S, Farmer B. Metoclopramide-induced cardiac arrest. Clin Pract. 2011;1(4):e83.
10. Cavero-redondo I, Álvarez-Bueno C, Pozuelo-Carrascosa DP, Díez-Fernández A, Notario-Pacheco B. Risk of extrapyramidal side effects comparing continuous vs. bolus intravenous metoclopramide administration: a systematic review and meta-analysis of controlled trials. J Clin Nurs. 2015;24(23-24):3638-46. 